\title{
Image Coding using Markov Models with Hidden States
}

\section{Forchhammer, Søren Otto}

Published in:

Data Compression Conference, 1999. Proceedings. DCC '99

Link to article, DOI:

10.1109/DCC.1999.785681

Publication date:

1999

\section{Document Version}

Publisher's PDF, also known as Version of record

Link back to DTU Orbit

\section{Citation (APA):}

Forchhammer, S. O. (1999). Image Coding using Markov Models with Hidden States. In Data Compression Conference, 1999. Proceedings. DCC '99 IEEE Computer Society Press.

https://doi.org/10.1109/DCC.1999.785681

\section{General rights}

Copyright and moral rights for the publications made accessible in the public portal are retained by the authors and/or other copyright owners and it is a condition of accessing publications that users recognise and abide by the legal requirements associated with these rights.

- Users may download and print one copy of any publication from the public portal for the purpose of private study or research.

- You may not further distribute the material or use it for any profit-making activity or commercial gain

- You may freely distribute the URL identifying the publication in the public portal

If you believe that this document breaches copyright please contact us providing details, and we will remove access to the work immediately and investigate your claim. 


\title{
Image Coding using Markov Models with Hidden States
}

\author{
Søren Forchhammer \\ Dept. of Telecommunication, 371, Technical University of Denmark \\ e-mail: sf@tele.dtu.dk
}

Lossless image coding may be performed by applying arithmetic coding sequentially to probabilities conditioned on the past data. Therefore the model is very important. A new image model is applied to image coding. The model is based on a Markov process involving hidden states. An underlying Markov process called the slice process specifies $D$ rows with the width of the image. Each new row of the image coincides with row $N$ of an instance of the slice process. The $N-1$ previous rows are read from the causal part of the image and the last $D-N$ rows are hidden. This gives a description of the current row conditioned on the $N-1$ previous rows. From the slice process we may decompose the description into a sequence of conditional probabilities, involving a combination of a forward and a backward pass. In effect the causal part of the last $N$ rows of the image becomes the context. The forward pass obtained directly from the slice process starts from the left for each row with $D-N$ hidden rows. The backward pass starting from the right additionally has the current row as hidden. The backward pass may be described as a completion of the forward pass. It plays the role of normalizing the possible completions of the forward pass for each pixel. The hidden states may effectively be represented in a trellis structure as in an HMM. For the slice process we use a state of $D$ rows and $V-1$ columns, thus involving $V$ columns in each transition.

The new model was applied to a bi-level image (S09 of the JBIG test set) in a two-part coding scheme. The transition probabilities of the slice process were estimated from the occurrence counts over all $V$ by $D$ rectangles within the image. The ideal code length without the model cost was measured to be 631,478 bits for $(V, D, N)=(4,3,2)$ and 571,690 bits for $(V, D, N)=(3,5,4)$. Coding the model parameters by quantizing each occurence count uniformly to 11 bits precision gave a total code length of 678,854 bits for $(V, D, N)=(4,3,2)$. This is more than the 584,688 bits for JBIG coding. The results of the new method could be improved by optimizing and using more efficient coding of the model parameters.

The formulas are identical to those of the CPH-MM [1], which by the additional requirement of rotational symmetry of the states of the underlying process ensures a stationary model description with a well defined entropy which may be bounded given the underlying process.

\section{References}

[1] S. Forchhammer and J. Justesen. Entropy bounds for constrained two-dimensional random fields. IEEE Trans. Inform. Theory, 45(1), Jan. 1999. 